\section{LA CRÍTICA DE PAUL KARL FEYERABEND AL MODELO NEO- POSITIVISTA DEL SIGNIFICADO}

\author{
María Teresa Gargiulo de Vázquez \\ Conicet-Universidad de Cuyo \\ gargiulomteresa@gmail.com
}

Cómo citar este artículo/Citation: Gargiulo de Vázquez, M.T. (2014). "La crítica de Paul Karl Feyerabend al modelo neopositivista del significado". Arbor, 190 (769): a168. doi: http:// dx.doi.org/10.3989/arbor.2014.769n5007

Recibido: 26 febrero 2014. Aceptado: 2 julio 2014.

RESUMEN: La crítica de Paul Feyerabend al modelo neopositivista del significado y su posterior abandono de las cuestiones referentes al lenguaje, entre otros giros de su pensamiento, ha dado materia a sus críticos y especialistas a tener una visión fragmentaria de su evolución intelectual. Su teoría pragmática de la observación ha sido explicada en el marco de su formación positivista o como una prolongación de su formación popperiana más no en continuidad con su posterior evolución intelectual. El presente artículo busca demostrar como el mencionado cambio radical de intereses no solo es lógico sino que guarda continuidad con sus posteriores denuncias. Cuando su teoría del significado es interpretada como una denuncia de los límites que supone el modelo axiomático de ciencia propuesto por el positivismo lógico se comprende que aquella constituyó para él la oportunidad de emprender su revisión crítica de la racionalidad científica. Pero una vez que con su teoría pragmática de la observación Feyerabend demuestra el contrasentido de erigir mediante la teoría semántica de la observación un modelo axiomático de ciencia, las teorías del significado dejan de tener sentido para él. De aquí que a su preocupación inicial por los asuntos del significado la califique posteriormente como inútil para una teoría del conocimiento y de la ciencia.

PALABRAS CLAVE: Feyerabend, teoría pragmática de la observación, teoría contextual del significado, principio de invariancia del significado, principio de deducibilidad.

\section{PAUL FEYERABEND'S CRITIQUE OF THE NEO-POSITIVIST MODEL OF MEANING}

Copyright: (C) 2014 CSIC. Este es un artículo de acceso abierto distribuido bajo los términos de la licencia Creative Commons Attribution-Non Commercial (by-nc) Spain 3.0.

ABSTRACT: Paul Feyerabend's critique of the neo-positivist model of meaning and his subsequent abandonment of language-related issues, among other turns of his thought, has given material to his critics and specialists by giving a fragmented view of his intellectual evolution. His pragmatic theory of observation has been explained in the framework of his positivist training or as an extension of his grounding in Popper's thought, but not as a continuum with the later development of this thought. This article seeks to show how this change in his interests is not only logical but forms a continuum with his subsequent critiques. When his theory of meaning is interpreted as a critique of the limits of the axiomatic model of science we can understood that this represented for him the opportunity to undertake a critical review of scientific rationality. However once Feyerabend demonstrates by his pragmatic theory of observation the absurdity of erecting an axiomatic model of science through the semantic theory of observation, the theories of meaning cease to make sense to him. Hence his initial concern for matters of meaning is dismissed by Feyerabend as useless for a theory of knowledge and science.

KEYWORDS: Feyerabend, pragmatic theory of observation, contextual theory of meaning, principle of meaning invariance, principle of deducibility. 


\section{INTRODUCCIÓN}

Feyerabend en su autobiografía (1994/1995, p. $67)^{1}$ reconoce haber adoptado, ente los años 1940 y principios de 1950, tesis características del positivismo lógico. Refiriéndose a este período intelectual se define a sí mismo como un empirista incondicional. Es efectivamente un empirismo anti-metafísico lo que lo conduce pensar en aquellos años que la ciencia es la base del conocimiento y a definir la ciencia como empírica. Sostiene que "las empresas no empíricas o son lógicas o carecen de sentido" (1994/1995, p. 69). Con firmeza insiste en la necesidad de eludir toda intervención de la metafísica en el campo de la ciencia. En su autobiografía, escribe: "yo me basaba en los datos sensoriales y la lógica (o lo que creía que era la lógica), [...y] replicaba diciendo que, por desgracia, los científicos no se habían liberado todavía de sus cascarones metafísicos" (1994/1995, p. 72).

No obstante, en cuanto Feyerabend estudia las Investigaciones Filosóficas de Wittgenstein y los problemas en torno a la interpretación de la teoría cuántica comienza una revisión crítica de su propia formación positivista. Esto da razón de ser a la fuerte crítica que dirige contra el modelo positivista del significado tanto en su tesis doctoral ${ }^{2}$ como en los artículos que publica entre los años 55 y 69.

A través de su participación en los debates surgidos en torno a Victor Kraft y de sus investigaciones en la London School of Economics bajo la supervisión de Popper, Feyerabend toma contacto con algunas de las críticas al positivismo lógico. Desde el 1949 hasta 1953 Feyerabend es uno de los estudiantes líderes del Círculo de Kraft, el cual es definido por él mismo como "una versión estudiantil del antiguo Círculo de Viena" (Feyerabend 1994/1995, p. 74). Kraft no solo dirige este círculo, sino que también supervisa sus estudios doctorales. Feyerabend (1978/1982, pp. 126-127 y $1987 / 2005$, pp. 96-97) asegura que gran parte de su tesis doctoral como muchos de sus primeros artículos son el resultado directo de los debates surgidos entre los miembros del Círculo y de las visitas ocasionales de Hollitscher, Felix Ehrenhaft, von Wright, Elizabeth Anscombe y Wittgenstein a aquellas reuniones. Aún más, Feyerabend reconoce explícitamente que Kraft "había anticipado algunas ideas que después se asociaron con Popper" (1994/1995, p.74). En la recensión que escribe a la Epistemología de Kraft (1963, p. 319) asegura que este había señalado la irracionalidad del empirismo lógico al pretender liberar la ciencia de sus ingredientes metafísicos. Estas demostraciones de Kraft facilitaron el posterior acercamiento de Feyera- bend a la filosofía de Popper y le ofrecieron abundante materia para sus ataques contra los distintos criterios positivistas del significado.

Casi simultáneamente a la formulación explícita del circulo de Viena de erigir una ciencia que excluya toda proposición metafísica nacen concomitantemente las primeras disputas positivistas en torno al significado. Pues dichas controversias surgen a partir de los distintos intentos por formular una teoría del significado que dé concreción a un modelo axiomático de ciencia.

Lo que se reconoce como el criterio empirista de significado cognoscitivo dicta que una oración constituye una aserción cognoscitivamente significativa solo si es analítica o bien, capaz, por lo menos en principio, de ser comprobable empíricamente. Este principio establece un criterio de demarcación entre ciencia y no ciencia. Puesto que todas aquellas aserciones que no sean analíticas o susceptibles de comprobación empíricas son categorizadas como metafísicas o seudo-hipótesis. Dichas aserciones al no afirmar nada, carecen de toda fuerza explicativa o predictiva y son calificadas, por tanto, como ajenas al cuerpo científico.

Evidentemente el criterio empirista del significado no es sino una caracterización general y básica de todo un proyecto que presento múltiples variantes, formulas y especificaciones. Basta para los fines de este trabajo explicar que la crítica de Feyerabend tiene como objeto, particularmente, las distintas variantes de lo que él (1958/1981, p. 20) reconoce como la concepción semántica de la observación, las cuales buscan postular una noción axiomática de ciencia.

La concepción semántica del significado abarca para Feyerabend tanto al instrumentalismo como al reduccionismo semántico de Carnap. El instrumentalismo interpreta la teoría científica como una herramienta de predicción y, en cuanto tal, sus enunciados teóricos carecen de significado descriptivo. Su función se limita a predecir el comportamiento de un fenómeno en lenguaje observacional. El reduccionismo, en cambio, dicta que las hipótesis teóricas poseen significado en la medida que pueden ser reducidas a un lenguaje observacional.

En sus primeros artículos Feyerabend se esfuerza por oponer a esta concepción semántica de la observación una teoría pragmática de la observación.

Existe de hecho en nuestros días una abundante bibliografía que analiza esta teoría pragmática de la observación como su propia teoría del significado (cf. Achinstein, 1964; Preston, 1997, pp. 23-39; 
Putnam, 1965; Shapere, 1966; Oberheim, 2006, pp. 43-70; Gentile, 2007, pp. 114-115) ${ }^{3}$. No obstante tales estudios se limitan a analizar aspectos restringidos de la teoría del significado del vienés: la analizan como una prolongación de las tesis de Popper (cf. Preston, 1997, pp. 9 y ss.; Bronncano, 1999, pp. 9-34; Watkins, 2000, p. 48; Oberheim, 2006, pp. 77-115 y Farrell, 2000 y 2003, pp. 151 y ss.), de las de Wittgenstein (Preston, 1997, pp. 23 y ss.), de las de Mach (Hentschel, 1985; Zahar, 1981), de las de Carnap (Gentile, 2007); o en continuidad con la filosofía neo-kantiana (Boyd, 1992 y Oberheim, Hoyninguen-Huene, 1997). Pero ninguna de estas aproximaciones da cuenta de la continuidad que existe entre su temprano interés por formular una teoría pragmática del significado y la posterior evolución de su itinerario intelectual, por lo cual pueden hacerse promotores de visiones fragmentarias e incompletas de su pensamiento.

Dicha situación parece ser deudora de la interpretación de Preston quien tiene el mérito de haber sido el primero en publicar en 1997 un estudio sistemático sobre la obra de nuestro pensador junto con su correspondiente biografía, titulada Feyerabend. Philosophy, Science and Society (1997). Preston (1999, p. 235) califica como un salto abrupto e inexplicable el abandono por parte del vienes de todas las cuestiones referidas al lenguaje en sus escritos posteriores a Contra el Método.

La pregunta que surge a partir de Preston es si existe o no una continuidad entre los primeros escritos donde expone su teoría pragmática del significado-y la posterior evolución de Feyerabend ${ }^{4}$.

El presente trabajo busca ser una refutación de la mencionada lectura que hace Preston. Particularmente nos interesa destacar la intención del vienés al desarrollar con su teoría pragmática de la observación y explicar cómo su inicial interés por el criterio positivista del significado no es contradictorio con el radical abandono que hace posteriormente de todas las cuestiones relativas al lenguaje. Para ello analizaremos su teoría pragmática de la observación como una denuncia de los límites y contradicciones que incurre la teoría semántica de la observación en cuanto que esta busca dar cumplimiento a un modelo axiomático de ciencia. Contextualizaremos su temprano interés por las teorías del lenguaje como parte integral de su contante preocupación por ampliar las definiciones lógicas o metodológicas de ciencia y racionalidad científica. De este modo ofreceremos una clave de análisis que permite comprender la perfecta continuidad existente en sus escritos. Primero, en orden a tener un conocimiento general de su teoría su teoría pragmática de la observación, analizaremos los principios generales que la constituyen (1) y expondremos como tal teoría contiene a la teoría contextual del significado (2). Luego, demostraremos como dicha teoría constituye para Feyerabend una oportunidad para repensar la ciencia desde una perspectiva más amplia, a saber, una racionalidad que abarque aquellos elementos metafísicos frente a los cuales el positivismo lógico -particularmente la teoría semántica de la observación- procura delimitar una definición negativa de ciencia (3). Finalmente, demostraremos cómo su teoría del significado implica una crisis de los principios básicos del positivismo lógico, a saber, el principio de autonomía de los hechos (4) y la tesis de la estabilidad del significado y, por tanto, como ella supone un fracaso para todo un modo de entender y definir la ciencia (5).

\section{LA TEORÍA PRAGMÁTICA DE LA OBSERVACIÓN}

A pesar de los ataques a lo que Feyerabend reconocía como la 'filosofía de Oxford', o precisamente, a ocasión de sus críticas contra la teoría pragmática y la teoría fenomenológica del significado, desarrolló lo que él mismo denomina su teoría pragmática de la observación (cf. Feyerabend 1962/1989, p. 147). En líneas generales según tal teoría el significado de un término no es una propiedad intrínseca suya, sino que depende del modo en que el término haya sido incorporado a una teoría (pp. 105-106).

El epistemólogo reconoce que tal teoría no constituye un aporte original en cuanto que esta fue postulada por algunos positivistas lógicos de la década del 30. De hecho, atribuye tal teoría a Carnap, a Neurath, e incluso a Popper (cf. Feyerabend 1962/1981b, pp. 49 y ss.; 1965a, p. 152 y pp. 212 y ss. y 1965/1981, p. 125). Pero considera que tal teoría pragmática de la observación al ser combinada con el instrumentalismo o con el reduccionismo semántico fue remplazada por una concepción semántica de la observación (Fayerabend, 1958/1981, p. 30, n. 20).

Cinco son los artículos donde se encuentra una exposición más completa y sistemática sobre su teoría del lenguaje: An Attempt at a Realistic Interpretation of Experience (1958), On the Interpretation of Scientific Theories (1960), Explanation, Reductión and Empiricism (1962) y On the "Meaning" of Scientific terms (1965), Problems of Empiricism (1965), Science without Experience (1969). 
Feyerabend declara explícitamente y en numerosos pasajes -como se irá viendo-su adhesión a una teoría pragmática de la observación, según la cual debemos distinguir entre el uso y el significado de una sentencia observacional. Al final de Explanation, Reductión and Empiricism (1962) escribe:

Me parece que el único camino posible estriba en la firme adhesión a la teoría pragmática de la observación. De acuerdo con esta teoría, como se recordará, debemos distinguir cuidadosamente entre las causas de la producción de cierta sentencia observacional, o los rasgos del proceso de producción, por una parte, y el significado de la sentencia así producida, por otra. Más específicamente, un ser sentiente debe distinguir entre el hecho de que posee una sensación, o disposición a la conducta verbal, y la interpretación de la sentencia que se pronuncia en la presencia de esta sensación, o que limita esta conducta verbal (Feyerabend 1962/1989, pp. 147-148)

Feyerabend (1958/1981, p. 19) sostiene que la distinción entre el uso y la interpretación -de la que puede ser objeto una sentencia protocolar- es clara e inconfundible. Se trata de dos actos enteramente distintos (p. 27).

Pues bien la teoría pragmática de la observación formulada por Feyerabend se ocupa primariamente del uso de las sentencias. En este sentido tanto Oberheim (2006, p. 48, n. 40) como Butts (1966, p. 385) destacan que la teoría pragmática de la observación tiene como objeto sentencias y no oraciones en cuanto que las primeras se refieren a eventos meramente físicos, mientras que las segundas poseen propiedades semánticas en las que se funda su función asertiva.

El uso que se hace de una sentencia atómica es un acto pragmático que depende de las condiciones de una situación física observable. Por ejemplo, la experiencia visual de 'ver un perro' determina las condiciones en las cual se hará uso de la sentencia atómica: 'hay una mancha perruna de color'. De estas experimentaciones u observaciones físicas depende la aceptación o rechazo de tal sentencia atómica. Se puede, incluso ofrecer una descripción detallada de este fenómeno particular, pero no por ello se comprende si efectivamente allí hay un perro. La sentencia observacional 'hay una mancha perruna de color' se limita a describir la situación experimental de 'ver un perro', o más propiamente, expresa la experiencia visual ante una determinada situación observable. Interpretar esta sentencia como una demostración de que efectivamente hay un perro para Feyerabend es un acto nuevo y distinto que confiere significado a su uso y que va más allá de los procesos observables. Primero, porque una imagen de un perro no es lo mismo que un perro. Segundo, la sentencia observacional 'hay una mancha perruna de color' podría ser objeto de distintas interpretaciones; podría interpretarse tanto cómo que hay un gato como un perro. En el acto de interpretación -explica Feyerabend (1958/1981, pp. 28-29)- intervienen múltiples supuestos teóricos que exceden la mera descripción de una experiencia observacional.

No se puede obtener una interpretación por la sola lectura de una situación observable. Prueba de ello -afirma el vienés- es que una misma base observacional puede ser compatible con las interpretaciones más diversas, e incluso mutuamente inconsistentes (1958/1981, p. 27). De este modo, Feyerabend prueba que ningún uso de las sentencias observacionales, ni de los fenómenos que acompañan sus aplicaciones en las situaciones observacionales pueden determinar la interpretación de aquellas. El acto de interpretación es un acto adicional que no está determinada lógicamente por la situación observable.

Feyerabend (1958/1981, p. 18) presenta las cuatro condiciones pragmáticas que determinan el uso de las sentencias básicas u observacionales:

1. Existe una situación física apropiada en cuanto provee una serie de operaciones que facilitan al observador decidir entre la aceptación o rechazo de la sentencia observacional.

2. La situación observable es de tal naturaleza que permite decidir rápidamente entre la aceptación o rechazo de la sentencia observacional.

3. En la medida que distintos observadores realicen una serie de operaciones en la misma situación observable es posible obtener una decisión unánime acerca de la aceptación o el recazo de la sentencia observacional.

4. La situación observable proporciona operaciones y datos relevantes que determinan causalmente la decisión o el rechazo de la sentencia protocolar. Tal decisión no puede estar fundada en la mera pronunciación de la sentencia o en el estado subjetivo del observador.

Estas condiciones estipulan la relación causal entre el comportamiento de los seres humanos y las situaciones físicas. Feyerabend parece asumir del conductismo de Skinner la distinción entre las propiedades pragmáticas y la interpretación de un lenguaje. 
Feyerabend no explicitó el contexto intelectual que le permitía realizar la distinción entre las características pragmáticas del lenguaje y su interpretación. No obstante, Eric Oberheim (2006, pp. 47-48) demuestra que tal distinción era parte, en aquel entonces, del conductismo radical de Skinner. Esta corriente psicológica ejerció una importante influencia entre los positivistas lógicos y, particularmente, en el materialismo eliminativo que mantuvo el epistemólogo en sus escritos sobre filosofía de la mente.

Esta corriente psicológica explica los fenómenos físicos observables a través del esquema de estímulo-respuesta, mientras que los fenómenos no observables quedan excluidos de su estudio. El epistemólogo emplea el esquema estimulo-respuesta para dar cuenta del proceso de producción de las sentencias observacionales. Pero, por otro lado, reserva una versión de la teoría contextual del significado al análisis de los factores extra-empíricos que intervienen en la interpretación de las sentencias.

Fiel a la concepción conductista de la percepción Feyerabend (1958/1981, p. 19) afirma que un observador es condicionado de tal modo por una situación observable particular (s) que produce ante ella una reacción específica $(r)$ mientras que se abstiene de producirla ante la ausencia de tal situación.

Las condiciones empíricas -explica el vienés- provocan una disposición, constituida por sensaciones físicas y psíquicas, por la cual se responde ante ellas con un determinado comportamiento, en este caso con una conducta verbal particular. En Explicación reducción y empirismo (1962/1989, p. 51) Feyerabend ilustra esta tesis con el siguiente ejemplo: un observador que tiene ante sí un cuervo, pronuncia la sentencia observacional 'Esto es un cuervo'. Produce tal sentencia debido a las impresiones, sensaciones y percepciones que tiene del ave. El observador no habría pronunciado tal sentencia si no hubiera tenido esas impresiones. La observabilidad está constituida por las reacciones condicionadas del observador ante eventos físicos que son traducibles en sentencias observacionales. Una sentencia observacional es la respuesta verbal emitida por el sujeto que se encuentra ante una determinada situación observable. Tal sentencia constituye una maquinaria sintáctica natural que imita pero no describe -subraya Feyerabend (1965a, pp. 214-215)- ciertas características de la respuesta a una experiencia particular pues una sentencia observacional es incapaz de ofrecer por sí misma una interpretación de los comportamientos verbales.
Los comportamientos verbales posibilitan que las sentencias observacionales puedan ser aceptadas o rechazadas independientemente de la interpretación de la que pueden ser objeto (1958/1981, p. 34). Las sentencias observacionales serán rechazadas en la medida que no imiten el comportamiento verbal. 0 , en el caso que expresen situaciones que son negadas por el observador (1965a, p. 215). Pero también puede ocurrir que ninguna de dos sentencias en competencia sea falseada en cuanto que ambas formulan un comportamiento verbal paralelo al del observador. En este caso se dispone de buenos instrumentos de predicción. Cabe aclarar que para el filósofo vienés las sentencias observacionales tienen un carácter estrictamente instrumental en cuanto que se limitan a reflejar o predecir el comportamiento del observador ante determinadas circunstancias.

Para precisar la naturaleza instrumental de estas sentencias Feyerabend (1962/1989, pp. 148-149 y 1965a, p. 214) concibe el siguiente caso hipotético: si se programara un robot introduciendo en este los datos de una teoría -junto con la información sobre las condiciones que caracteriza un cierto dominio observacional-, este imitaría de un modo exacto el comportamiento verbal humano. Evidentemente el robot no estaría cargado de ningún dato o información fenomenológica al estar desprovisto de órganos sensibles y de experiencia perceptual. No obstante, podría responder del mismo modo que los seres humanos ante una determinada situación. Tendría la habilidad de aceptar o rechazar ciertas sentencias al confrontarlas con estímulos de cierto tipo. De este modo, el comportamiento del robot que está cargado con una teoría -entendida como un instrumento de predicción- y el del observador que no posee tal teoría pero si dispone de experiencia perceptual, sería exactamente el mismo. Las predicciones del robot se identificarían con las sentencias observacionales que los seres humanos producen ante las mismas situaciones empíricas. Este acuerdo entre el comportamiento del robot y el de los seres humanos ofrece únicamente de un criterio para medir el éxito predictivo de las teorías en cuestión. Permite evaluar si las teorías en competencia son buenos instrumentos de observación.

La concordancia de comportamiento o las reacciones mutuamente consistentes a las que puede dar lugar una situación observable en distintos observadores es independiente de la interpretación que se le concede a la misma. No existe relación alguna entre el sentido de los eventos físicos y las reacciones intersubjetivas que estas provocan (1962/1989, p. 148). 
Feyerabend (1962/1989, p. 50) se aleja así del conductismo postulado durante un tiempo por Carnap y Neurath para quienes la contrastación intersubjetiva es garantía suficiente de objetividad. Contra ellos, el filósofo vienés afirma que la concordancia de comportamiento o la intersubjetividad no es suficiente para atribuir a las teorías o sentencias un carácter descriptivo, es decir, para concebirlas como una explicación hipotética de lo que sucede en el mundo. Insiste que el hecho de que cierta sentencia pertenezca al lenguaje observacional no permite hacer inferencia alguna respecto al tipo de entidades al que se referirían (1962/1989, pp. 52-53 y p. 56).

Para evaluar si las sentencias o teorías ofrecen descripciones del mundo es preciso recurrir a factores extra-empíricos. Pues bien, cabe preguntarse ¿cuáles son estos factores extra-empíricos para Feyerabend?, ¿cuáles son las condiciones que determinan el significado de una sentencia? ¿Cómo es posible determinar la correlación entre las reacciones humanas y un evento físico, entre las sentencias observacionales de una teoría y una situación del mundo?

El significado de una sentencia -según Feyerabend (1958/1981, p. 27 y 1960, p. 250)- es fruto de una convención. Mientras que el uso de una sentencia observacional está determinado causalmente por las características pragmáticas recién enumeradas, el significado de esta depende de las teorías que se eligen para interpretarlas. En una recensión que escribe a las Conjeturas y Refutaciones de Popper, el vienés (1965b, p. 213) sostiene que según su teoría pragmática de la observación el significado de las oraciones observacionales está determinado por las teorías con las cuales aquellas están conectadas.

Aun cuando un enunciado pertenezca al dominio observacional, o cuando su producción vaya acompañada de sensaciones muy intensas, Feyerabend (1962/1989, p. 56) explica que se es libre de interpretarlo de acuerdo con la teoría o puntos de vistas generales con los que uno decide comprometerse. Si se decide adoptar una nueva teoría, con su respectiva ontología, entonces también las oraciones observacionales adoptaran un nuevo significado. Feyerabend (1958/1981) presenta como su 'tesis I', la siguiente sentencia: "la interpretación de un lenguaje observacional está determinada por las teorías que usamos para explicar lo que observamos, y esta cambia tan pronto como aquellas teorías cambian" (p. 31). Una sustitución de teorías exige una consiguiente modificación del significado de sus términos.
La capacidad del hombre para crear conceptos o teorías es infinita. Incluso en el caso de que una situación observable parezca sugerir una única interpretación o teoría como universalmente verdadera, es posible -prueba Feyerabend (1958/1981, p. 24) - inventar un nuevo proyecto conceptual, en la medida que se dispongan de imágenes metafísicas del mundo. Nada puede limitar esta libertad de interpretación -sostiene en Explanation, Reductión and Empiricism (1962/1989, p. 56)- excepto las mismas restricciones que impone la misma ontología o tradición que se elige.

La interpretación de los términos científicos no emerge de la cerrada atención a los 'hechos' pues -tal como se ha visto- pueden ser objetos de múltiples e incluso divergentes interpretaciones. Esto conduce al filósofo vienés (1960/1981a, p. 42) a reconocer que la interpretación de los términos científicos no depende de su conexión con la experiencia, a través de sentencias observacionales, sino de los elementos metafísicos contenidos en la teoría. Necesitamos -afirma Feyerabend (1958/1981) - "una fuente no-observacional para las interpretaciones. Tal fuente es provista por la especulación (metafísica)" (p. 36). Es decir, se interpretan las sentencias conforme a la ontología que informa la teoría elegida. A cada lenguaje se le aplican las connotaciones ontológicas propias del todo teórico.

El epistemólogo vienés concibe la ciencia no como una construcción formal a la que debe ser asignado un significado sino como un complejo de proposiciones ya significantes. La teoría, en cuanto que está informada o travesada por una ontología determinada, posee una interpretación acerca del mundo o del ámbito circunscripto del que se ocupa. Feyerabend asegura que en la ciencia empleamos para comunicarnos hacemos uso de presupuestos, es decir, de suposiciones acerca de cómo es el mundo (1958/1981, p. 35) las cuales no pueden ser comprobadas empíricamente y en este sentido las designa como metafísicas (1960/1981a, p. 42).

Feyerabend utiliza frecuentemente la noción de 'metafísica' en el sentido popperiano, es decir, para referirse a todo aquello que no puede ser objeto de falsación empírica (cf. Feyerabend, 1960/1981a, pp. 42-43). En este sentido, una teoría será metafísica en la medida que no sea posible especificar un resultado experimental que pueda ponerla en peligro $u$ obligarnos a abandonarla. Feyerabend asume esta concepción de la metafísica no como una tesis pro- 
pia sino en orden a llevar cabo una reducción al absurdo de la misma, es decir, con el fin de mostrar la contradicción intrínseca que supone.

Además de esta referencia a la concepción popperiana de metafísica, el epistemólogo con la noción de metafísica se refiere, en un marco más general, a todos aquellos elementos que no son susceptibles de comprobación empírica y en este sentido coincide con lo que el positivismo lógico en general entiende por metafísica (cf. Feyerabend, 1962/1989, p. 17 y p. 40; 1970/1989, pp. 140-141). La metafísica es caracterizada dialécticamente por el positivismo como lo no científico, extendiéndose así a todo juicio de valor, prejuicio o concepción ontológica, estética, moral, política o religiosa. Pues bien, cuando Feyerabend utiliza esta noción ambigua e imprecisa de metafísica le interesa demostrar la paradoja por la cual todos aquellos elementos que el positivismo lógico considera como carentes de sentido -pues no pueden ser criticados y desarrollados según sus 'cánones de racionalidad'constituyen la materia que fecunda la tarea científica.

Por ontología Feyerabend entiende las visiones del mundo que informan la actividad científica. Reconoce como ontológico a todo sistema conceptual comprehensivo lo suficientemente rico como para esbozar una explicación de la totalidad de las apariencias físicas y, por tanto, capaz de sustituir a las demás cosmovisiones como un todo (cf. Feyerabend, 1958, pp. 7879 у рp. 90-91; 1961/1999, pp. 52-54; 1962/1981a, p. $323 ; 1962 / 1989$, p. 38 , pp. $77-78$ у pp. $137-138$; 1965/1981, pp. 109-110; 1967, p. 40; 1975/1992, pp. $102-103$ у 1977 , p. 365, n. 1).

Feyerabend (1963/1999, pp. 87-88) asegura que entiende la ontología en el mismo sentido que Quine, es decir, como visiones contingentes o eventuales que facilitan descripciones hipotéticas acerca de la estructura y naturaleza del mundo físico. Feyerabend asume la concepción de ontología de Quine (1986 y 1992) como aquella ciencia relativa a la elección de una eventual red lingüística dentro de la cual reificamos el material observacional. Pero la asume en orden a reducir al absurdo la pretensión de que la ontología se limite a preguntarse por la existencia de entidades dentro de un discurso lingüístico. En sus numerosos artículos en torno a la mecánica cuántica denuncia insistentemente la necesidad de que la mecánica cuántica posea una autentica referencia ontológica y no únicamente un marco ontológico que explique el comportamiento cuántico de acuerdo a sus propios principios (cf. Feyerabend, 1958, p. 80; 1962/1981a, pp. 312-313 y 1966a, pp. 416-417).
En este sentido tampoco puede identificarse la posición de Feyerabend con la conocida distinción carnapiana entre cuestiones internas y cuestiones externas, entre metafísica y ontología. Pues para él no tiene sentido limitarse a preguntar por la existencia de entidades únicamente dentro del marco de una teoría u ontología, sino que es imperativo que la ciencia indague acerca cuáles son las entidades que existen, en general, y por tanto que se ocupe de lo que Carnap reconoce como cuestiones externas y por ende metafísicas.

\section{ASIMILACIÓN Y CRÍTICA A LA TEORÍA CONTEX- TUAL DEL SIGNIFICADO}

John Preston (1997, p. 30) concibe la 'tesis I' -donde Feyerabend parecería concentrar toda su teoría del significado- como una concreción particular de la teoría contextual del significado. La 'tesis I', según él, estaría contenida o implicada lógicamente en la teoría contextual pues mientras esta última se refiere al significado de todos los términos científicos, aquella se aplica únicamente al lenguaje observacional. En pocas palabras: la teoría contextual del significado abarcaría la 'tesis I' al aplicarse a cualquier tipo de lenguaje.

Preston restringe la aplicación de la 'tesis I' de Feyerabend al lenguaje observacional. Efectivamente Feyerabend, en la formulación explícita que hace de tal tesis en su artículo An Attempt at a Realistic Interpretation of Experience (1958/1981, p. 31), hace referencia únicamente a los lenguajes observacionales pues su intención aquí es presentarla como una objeción a la postulación positivista de términos observacionales puros y neutros. No obstante, como se verá a lo largo de este capítulo, Feyerabend en su argumentación lógica y en sus ilustraciones históricas refiere su 'tesis I' a todo el lenguaje científico, tanto a lo que el positivismo lógico reconoce como oraciones teóricas, como a las observacionales e incluso al lenguaje cotidiano.

Eric Oberheim sostiene que la única diferencia entre la teoría contextual del significado y la teoría de Feyerabend radica en que la primera se aplica a los 'términos' mientras que la tesis del epistemólogo se refiere a las 'oraciones'. Feyerabend-según Oberheim (2006, p. 63)- en su teoría del significado extiende la teoría contextual de tal modo que abarca no solo a los términos teóricos de las teorías científicas sino a todo el lenguaje científico, cumpliéndose así una relación diametralmente opuesta a la postulada por Preston. 
La 'tesis I' parece ser menos general que la teoría contextual pero de hecho la abarca y la contiene, pues la interpretación de los términos está contenida en la significación de las oraciones.

Feyerabend defiende una teoría contextual del significado. Pero también advierte y critica las consecuencias que pueden seguirse de un contextualismo extremo. Por un lado, Feyerabend es reacio a una definición excesivamente amplia del contexto de significación. En este sentido crítica a Hanson quien en su obra Patterns of Discovery (1958) está dispuesto a incluir en el contexto de significación cualquier idiosincrasia o comportamiento sea de un científico particular o de un grupo de científicos (cf. Feyerabend 1960, pp. 249-250). El filósofo vienés restringe el contexto de significación a la ontología que atraviesa el todo teórico. Los términos científicos adquieren significado en virtud de la implícita descripción del mundo que ofrece la ontología de la teoría a la que pertenecen.

Por otro lado, rechaza tal contextualismo en cuanto supone la imposibilidad lógica de llevar a cabo experimentos cruciales e independientes de una teoría. Feyerabend asume una versión de la teoría contextual del significado pero no descarta -como se verá más adelante- la posibilidad de usar evidencia empírica para falsear las teorías. En 1960 Feyerabend escribe una recensión a la obra mencionada de Hanson donde critica justamente esta consecuencia negativa que se sigue de la teoría contextualista del autor. Hanson defiende una teoría contextual del significado según la cual el significado de los términos depende del contexto teórico en el que tiene lugar. Pero Hanson deduce de esta teoría contextual del significado un resultado que según Feyerabend es preciso evitar: Hanson va demasiado lejos al afirmar que la mecánica clásica no permite formular una sentencia que pueda ser considerada como evidencia para su propia falsación. Para Hanson siempre se dispone el contenido empírico u las oraciones observacionales de tal modo que corroboren la teoría de la que forman parte. No solo es psicológicamente inconcebible sino que por principio es imposible que una teoría ofrezca un contenido observacional capaz de objetarla o ponerla en duda. Feyerabend le objeta a Hanson que aun cuando el significado de un término sea definido por el rol que juega dentro de una determinada teoría, es posible llevar a cabo una falsación en la medida que los términos hayan sido definidos por una teoría distinta a la que objetan. En una nueva teoría los términos adquieren un nuevo significado $y$, en consecuencia, ofrecen una nueva descripción del contenido em- pírico ${ }^{5}$. El problema que no advierte Hanson es que las teorías no pueden ser falseadas desde sí mismas. Permaneciendo fiel a su formación popperiana, Feyerabend (1960, pp. 248-249 y 1964b, p. 266) afirma que este nuevo contenido empírico constituye una oportunidad de falsación de la antigua teoría antes que una instancia de confirmación o verificación.

Feyerabend muestra además la necesidad de que aquellos que sostienen una teoría contextual del significado, acepten como una prolongación de la misma un pluralismo metodológico. Pues solo considerando teorías alternativas, fácticamente adecuadas pero mutuamente inconsistentes, se pueden evitar los dogmatismos propios de un contextualismo extremo y aumentar el contenido empírico de la ciencia. En Explanation, Reduction and Empiricism (1962) presenta de un modo claro la continuidad existente entre su teoría contextual del significado y su propuesta de un pluralismo metodológico:

Al igual que el significado de un término no es una propiedad intrínseca suya, sino que depende del modo en que el término haya sido incorporado a una teoría, del mismo modo el contenido total de una teoría ( $y$, por tanto, de nuevo, el significado de los términos descriptivos que contiene) depende de la manera que es incorporada tanto al conjunto de sus consecuencias empíricas como al conjunto de todas las alternativas que están siendo discutidas en un momento dado. Una vez adoptada la teoría contextual del significado, no hay razón para limitar su aplicación a una teoría singular, o a un lenguaje singular, especialmente si los límites de tal teoría o tal lenguaje casi nunca están bien definidos. Las consideraciones anteriores han mostrado, además, que la unidad involucrada en la contrastación de una teoría específica, no es esta teoría junto con sus propias consecuencias, sino toda una clase de teorías mutuamente incompatibles y fácticamente adecuadas. En consecuencia, tanto la consistencia como consideraciones metodológicas sugieren tal clase como contexto en el que han de clarificarse los significados (Feyerabend, 1962/1989, pp. 105-106).

Así cómo el significado de los términos solo puede ser clarificado en relación con la teoría de la que forman parte, de modo análogo la validez de una teoría solo puede ser definida mediante una contrastación con teorías alternativas.

La teoría contextual que postula Feyerabend supone que los términos adquieren significado por la ontología de la teoría a la que pertenecen. Pero se diferencia de un contextualismo extremo que cierra toda posibilidad de que los enunciados sean falseados. 


\section{INVERSIÓN DEL MODELO POSITIVISTA DEL SIGNI- FICADO Y LA CONSECUENTE CRISIS DE UN MODO DE ENTENDER LA CIENCIA}

Feyerabend señala la necesidad de que el empirismo lógico abandone algunos de sus supuestos erróneos y para ello reintroduce la teoría pragmática de la observación propuesta por los positivistas lógicos en la década del $30^{6}$. Explica que cuando la teoría pragmática de la observación fue combinada con el instrumentalismo o con el reduccionismo semántico de Carnap surgen estos supuestos erróneos. Según el instrumentalismo, las teorías son instrumentos que predicen -en términos del vocabulario observacional- el comportamiento de un conjunto de fenómenos. Luego, cualquiera sea la interpretación del lenguaje observacional, esta sería independiente de la superestructura teórica. El reduccionismo semántico de Carnap, por su parte, también contempla la posibilidad de otorgar significado a los términos de una teoría en términos de un lenguaje más básico (cf. Feyerabend 1958/1981, p. 30, n. 20)

El filósofo de las ciencias (1960/1981a, p. 49) asegura que las dificultades del positivismo no pueden ser superadas por una nueva e ingeniosa conexión entre los términos teóricos y los términos observacionales, sino solamente por el abandono completo de la idea que el significado de los términos teóricos depende de tal conexión. Rechaza definitivamente la distinción propia del positivismo lógico entre el lenguaje observacional y el lenguaje teórico (Cf. Feyerabend 1958/1981, p. 27 y pp. 32-33; 1959a, p. $82 ; 1959$ b, p. 443; 1965a, p. 198 у рp. 219-224; 1960/1981a, pp. 37-43; 1962/1981b, pp. 45-47 у 1969/1981, pp. 132-135). La única diferencia -según Feyerabend- entre las sentencias observacionales y las demás proposiciones radica en las circunstancias psicológicas o en contexto causal en las que estas son pronunciadas. Las sentencias observacionales no se distinguen de las demás por su contenido, es decir, por limitarse a describir los datos puros de la observación, sino únicamente por la causa de su producción. Se dicen oraciones observacionales aquellas que obtienen sin vacilación el asentimiento o rechazo del observador en cuanto expresan una situación fácilmente observable:

Una sentencia observacional se distingue de otras sentencias de una teoría no por su contenido, como se hacía en el primer positivismo, sino por la causa de su producción, o por el hecho de que su producción se adecúa a ciertos patrones conductistas (Feyerabend 1962/1989, p. 52) 7 .
Feyerabend admite la existencia de una base observacional en la cual se cumplen las características pragmáticas mencionadas más arriba y en función de la cual es posible, a través de experimentos cruciales, decidir la aceptación o rechazo de una teoría. Tal como señala Dudley Shapere (1981, p. 47) Feyerabend no se opone a la idea de una observación independiente de una teoría pero si a la existencia de un lenguaje observacional teóricamente independiente o, para ser más precisos, se opone a concebir las sentencias observacionales como lingüísticamente significativas ${ }^{8}$.

Una vez que estas sentencias observacionales son interpretadas a la luz de las teorías adoptadas queda sellada la unidad interpretativa entre la teoría y los enunciados observacionales. En este sentido -afirma Feyerabend- la interpretación de las oraciones observacionales, es completamente teórica. Explica que el significado de cada término depende del contexto teórico en el que tiene lugar. Las palabras no significan nada aisladamente; ellas obtienen su significado al ser partes de un sistema teórico. Los enunciados observacionales carecen por sí mismos de significado. Enuncian que ante una situación particular sucede un fenómeno determinado pero no explica por qué sucede; la explicación o interpretación del tal fenómeno solo puede ser facilitada por una teoría. Solo pueden ser interpretados en la medida que son asumidos e incorporados a una teoría (cf. Feyerabend 1962/1989, pp. 105-106; 1965a, p. $180 ; 1965$ b, p. 88 y 1969/1981, p. 133).

Feyerabend en su teoría del significado parece llevar hasta sus últimas consecuencias la argumentación que su maestro exponía en Conjeturas y Refutaciones (cf. Popper, 1972, pp. 153-155), donde reformula lo expuesto veinte años antes en La Lógica de la Investigación científica (1934). En este sentido se cree que es acertada la observación de Preston (1997, p. 46) cuando afirma que la teoría pragmática de la observación de Feyerabend constituye el más inflexible intento de desarrollar la misma línea argumentativa de Popper. Aun cuando años más tarde, en La ciencia en una Sociedad libre (1978/1982, pp. $64-65$, n. 98), Feyerabend niegue que la idea de que todo hecho experimental es esencialmente teórico sea una tesis original de Popper y señale como sus autores a Newton, Mill, Goethe, Mach, Boltzmann, y hasta al mismo Aristóteles. En su libro Feyerabend 's Philosophy (2006) Oberheim ha estudiado el pensamiento del autor desde los originales lo cual le permite conocer las variaciones y correcciones que Feyerabend fue introduciendo en las distintas edi- 
ciones o publicaciones de una misma obra. Dicha investigación le permitió descubrir, por ejemplo, el hecho de que en la colección de artículos que publico en el volumen I y II de los Philosophical Papers en 1981, Feyerabend omite todo reconocimiento a Popper (pp. 2-3). Esto explica que en sus posteriores declaraciones no reconozca la influencia que ejerce Popper en su teoría del significado.

El filósofo vienés no se limita a sostener que el núcleo observacional posee una 'carga teórica' tal como ya afirmaban Hesse y Hanson, sino que dando un paso más allá, afirma que no existe un núcleo observacional; todos los términos son completamente teóricos (1965a, p. 216 y 1981). Esta tesis fundamental ha sido ignorada cuando no malinterpretada por parte de sus críticos (cf. Bogen y Woodward, 1992; Butts, 1966; Chalmers, 1985; Churchland, 2000; Hardcastle, 1994; Hooker, 1973; Hull, 1972; Kordig, 1971; Preston, 1997, pp. 40 y ss.; Quine, 1993; Shea, 1971 y Shapere, 1966). De aquí que Feyerabend dé cuenta, en una extensa nota al pie de su Ciencia en una Sociedad Libre, de sus distintos intentos por clarificar o reformular estas tesis a lo largo de la gran mayoría de sus primeros artículos y particularmente en las dos primeras ediciones de su Tratado contra el método al que se refiere bajo la sigla TCM.:

[...], considero los enfoques sujeto-objeto del conocimiento como intentos especialmente problemáticos de comprender nuestro papel en el mundo (TCM, capítulo 17), rechazo las metodologías que imponen reglas desde el exterior y en su lugar recomiendo un estudio funcional del procedimiento científico (TCM, pp. 244 ss., subsecciones 2, 5, 6 y 7 p. 254), así como una "crítica cosmológica" de las metodologías (TCM, p. 196), y así sucesivamente.

Veamos con más detenimiento el problema de la carga teórica, que desempeña un papel importante en la imagen que CS [Curthoys y Scuting] dan de mí. Al hablar de carga teórica se da a entender que en todo enunciado observacional hay una parte teórica y otra no teórica que la sostiene. Me he opuesto a esta idea en todos mis escritos, desde mi tesis doctoral (1951) a la última edición (en rústica) de TCM. En el volumen de 1958 de los Proceedings of the Aristotelian Society propuse que se interpretaran los enunciados observacionales en términos exclusivamente teóricos; en "Das Problem der Existenz Theoretischer Entitäten", Kraft Festschrift, Viena Springer Verlag, 1960, demostré que la idea de la carga teórica lleva a consecuencias paradójicas; en "Explanation, reducciton and empircism", que aparece en la bibliografía de CS, traté de explicar psicológicamente (esto es, sin hacer referencia a división alguna en el contenido del enunciado o en la naturaleza del objeto a que se refiere) lo que generalmente se denomina "núcleo observacional" de un enunciado observacional; en "Science without experiencie", Journal of Philosophy, vol. LXVI, 1969, reeditado en el artículo "Contra el método", que también recogen CS en su bibliografía, fortalece más mis argumentos contra la carga teórica. Esta breve nota que atrajo sobre mí las iras de Ayn Rand (véase su cata abierta del 3 de abril de 1970 a todos los filósofo norteamericanos y su artículo en el Objectivist de marzo de 1970, que guarda muchas semejanzas con la recensión de nuestros amigos marxistas), se resume en las páginas 256 ss. de TCM. CS debían de desear ardientemente hacer de mí un empirista para pasar por alto estos testimonios en contra (Feyerabend 1978/1982, pp. 183-184, n. 9).

Los signos descriptivos de un lenguaje están en estrecha dependencia con los prejuicios o ideas metafísicas que se tienen acerca de las cosas y de sus propiedades (cf. Feyerabend 1958/1981, p. 29). Pues la interpretación que hace una teoría científica de un estado de problemas está determinada por su visión metafísica del mundo. De aquí que el epistemólogo concluya que no es posible distinguir entre 'significado metafísico' (o 'sinsentido') y 'significado científico'. Admite una única diferencia entre la interpretación científica y la metafísica, -siendo así fiel al criterio de demarcación popperiano- y esta consiste en que inicialmente la primera es falsable, mientras que la segunda posee un contenido que no es susceptible originariamente de falsación empírica (1960/1981a, p. 43). No obstante, esto no exime -según Feyerabendque los resultados de la especulación metafísica deban ser en algún momento falsables y se identifiquen, de este modo, con las proposiciones científicas (p. 36).

Feyerabend pretende invertir el modelo positivista del significado. El título de su artículo Science without Experience (1969/1981, p. 133) sugiere justamente esta oposición dialéctica al positivismo lógico. Para él es posible construir un modelo de ciencia sin experiencia, pues las teorías científicas poseen en sí mismas una interpretación o significado que es independientemente de la experimentación -tal como es concebida por el empirismo lógico-, mientras que el significado de las experiencias y el de las sentencias observacionales que la describen está siempre determinado por las teorías a las que pertenecen.

El significado -asegura el filósofo de las ciencias (1996/1999, p. 147; 1965a, pp. 156 y ss.)- se filtra 
en sentido opuesto al postulado por el positivismo ortodoxo. Cada uno de los términos observacionales o protocolares adquiere significación o propiedades semánticas propias y exclusivas en cuanto que participan en la estructura interna de una teoría. Las propiedades semánticas y el contenido de una observación u oración atómica provienen de las teorías a partir de las cuales se hace la lectura de las mismas. En su autobiografía escribe:

Los positivistas eran partidarios de una "filtración ascendente" del significado, como Meehl la llamaba: los enunciados de la observación (los situábamos en la parte inferior de nuestros diagramas) son significativos, mientras que los enunciados teóricos tomados por sí mismos no lo son, sino que reciben el significado a través de vínculos lógicos que los unen a los enunciados de la observación. Continuando la tendencia inaugurada en mi artículo de 1958, yo sostenía que los significados se mueven en la dirección contraria. Los datos sensoriales, en y por sí mismos, carecen de significado: solo son. Si a una persona se le dan datos sensoriales y nada más estará completamente desorientada. El significado proviene de las ideas. El significado, por tanto se "filtra en sentido descendente", desde el nivel teórico hasta el nivel de la observación (Feyerabend, 1994/1995, p. 113) ${ }^{9}$.

Pero Feyerabend no se limita a invertir el modelo positivista del significado. Sus críticas alcanzan a todo un modo axiomático de entender la ciencia, del cual la teoría semántica de la observación no es sino uno de los intentos que busca concretarla. Pues al dar cuenta cómo el significado de las oraciones observacionales depende de los elementos metafísicos u ontológicos que atraviesan las teorías está demostrando, en definitiva, el fracaso del mismo proyecto del positivismo lógico por definir la ciencia en oposición dialéctica con la metafísica.

Feyerabend explica que aquellos elementos frente a los cuales se procura delimitar una definición negativa de ciencia, constituyen paradojalmente el seno del quehacer científico. Pues si aquellos elementos o supuestos que el positivismo lógico reconoce como metafísicos son la causa y raíz del significado y sentido de toda proposición científica, estos no pueden ser discriminados como ajenos o extraños al quehacer científico.

A través de su teoría pragmática de la observación, de su doctrina de la inconmensurabilidad, su tesis de la proliferación teórica y de su anarquismo epistemológico Feyerabend emplea una noción ambigua de metafísica cuyo contenido varía según sea el interlocutor con el que discuta. En líneas generales, y atendiendo al sentido constante que el positivismo lógico, Popper, Lakatos y Kuhn refieren a la metafísica se puede decir que esta es concebida dialécticamente como lo no-científico. Pues bien, Feyerabend en sus razonamientos por reducción al absurdo, desarrollados en sus distintos abordajes de las mencionadas cuestiones, expone las contradicciones que implica esta noción de metafísica en la medida que demuestra que se no puede entender la ciencia sin estos elementos que sus interlocutores reconocen como metafísicos.

\section{4. el atAQUe AL PRINCIPIO de AUtonomía de LOS HECHOS}

Feyerabend argumenta que si el significado de las sentencias observaciones depende de los supuestos ontológicos de las teorías debe admitirse que una sustitución de teorías, con su consiguiente sustitución de ontología, implica una modificación del significado tanto de las sentencias que el positivismo reconoce como teóricas como de las observacionales. Esta tesis, que constituye un antecedente de su doctrina de la inconmensurabilidad, supone una crisis de los principios fundamentales sobre los cuales descansa según él- el modelo axiomático de ciencia, a saber, el principio de autonomía de los hechos y el principio de estabilidad del significado.

En el presente y en el próximo se detallan las objeciones que Feyerabend dirige contra estos dos principios con los que el positivismo lógico busca garantizar la objetividad y el progreso científico.

Feyerabend (1963/1999, pp. 91 y ss.; 1962/1981b, p. 46; 1965a, p. 216 y p. 174) cuestiona lo que era para él la piedra angular sobre la que se sostenía el positivismo lógico, a saber, el principio de autonomía de los hechos, según el cual los hechos que corresponden al contenido empírico de una teoría 'están ahí o son dados, independientemente de que se consideren o no teorías alternativas a la imperante ${ }^{10}$.

Con su teoría pragmática de la observación ataca el rol fundamental que la teoría semántica de la observación concede a las oraciones observacionales o protocolares y, en consecuencia, a su modelo de comprobación teórica. Las teorías son comprobables -según el positivismo lógico- en la medida que sus sentencias teóricas son reducibles a sentencias protocolares que reciben su significado directa o indirectamente de la experiencia dada. Las sentencias protocolares $u$ observacionales se limitan a describir el dominio de los 
hechos y se constituyen en jueces imparciales y neutros -explica el vienés (1960, p. 247; 1962/1989, p. 49 у pp. $57-59 ; 1962 / 1981$ b, p. 46 y 1963/1999, p. 91)-en función de los cuales se comprueban las teorías científicas. Contra este modelo de comprobación Feyerabend propone un análisis pragmático según el cual se distinguen las propiedades pragmáticas del lenguaje y su interpretación. Con respecto a la interpretación asegura que esta no está determinada por la situación observable sino por el marco teórico aceptado y, en este sentido, los enunciados teóricos y observacionales, no son entidades independientes vinculadas por reglas de correspondencia, sino que conforman un todo indivisible (cf. Feyerabend, 1994/1995, pp. 133134). La evidencia experimental no consta solo de hechos puros y simples, sino, y sobre todo, de hechos analizados, modelados, construidos e interpretados de acuerdo con alguna teoría: "No hay ningúna 'experiencia neutra', con la cual pueden ser confirmadas las teorías o contra la cual las teorías puedan ser directamente falseadas" (1960/1999, p. 48).

Feyerabend al negar la existencia de un núcleo empírico con un significado estable, destruye, en consecuencia, no solo el modelo de comprobación teórica sino también el mismo criterio con el que el positivismo lógico busca garantizar la objetividad científica. Estas consideraciones son explicitas en la conclusión de su artículo Explicación, reducción y empirismo (1962):

Considerando que las percepciones están influidas por la creencia en teorías, ese criterio podría parecer arbitrario. No obstante, se ve fácilmente que no puede ser substituido por un criterio menos arbitrario y más "objetivo". ¿Cuál sería dicho criterio? Sería un criterio basado en la conducta no relacionada con ningún elemento teórico -y esto es imposible (véase mi critica anterior a la teoría de los sense-data)- o sería la conducta vinculada a una teoría irrefutable y firmemente establecida, lo cual es igualmente imposible. Hemos de concluir, por consiguiente, que no puede darse una descripción formal y "objetiva" de la explicación (Feyerabend, 1962/1989, p. 149).

La crítica de Feyerabend se dirige, en última instancia, contra un modelo axiomático de ciencia en cuanto que presenta a la ontología como el corazón de una teoría científica en virtud de la cual adquieren significado cada una de sus proposiciones, incluso aquellas proposiciones que el positivismo lógico reconoce como observacionales.

Ahora bien, Feyerabend (1962/1989, p. 147, n. 97) contempla la aparente tensión -que le fue se- ñalada por Herbert. Feigl- entre su crítica al principio de autonomía de los hechos y su simultánea defensa de la falsación. Pues esta última exige una base observacional neutra e imparcial en virtud de la cual sea posible decidir cuál de las teorías confrontadas ha de ser abandonada. Por lo que parecería que el significado de la sentencia observacional debería ser independiente de las teorías en cuestión (1958/1981, pp. 31-32; 1965/1981, p. 116 y p. 121). Es esta misma objeción la que luego le dirigieron críticos como Preston (1997, p. 60) y Robert Butts (1966, p. 387 y pp. 390-391).

Una objeción análoga fue formulada reiteradamente para mostrar la contradicción que existe entre su tesis de la inconmensurabilidad y el principio de proliferación teórica (cf. Butts, 1966, p. 391; Klimovsky 2001, p. 382; Achinstein, 1968, p. 93 y Townsend, 1970, p. 208), a saber, si las teorías fijan el significado de los enunciados observacionales, a la hora de contrastar dos teorías inconmensurables no habrá ningún enunciado común a las teorías rivales en función del cual puedan ser contrastadas. Ninguna de las dos teorías podría contradecir ni estar de acuerdo con la otra. Cada una de ellas simplemente hablaría de sí misma, de cosas acerca de las cuales ninguna otra teoría podría decir algo en absoluto. Esto hace difícil ver como dos teorías pueden ser explicaciones alternativas de un mismo dominio.

La respuesta más clara que ofrece Feyerabend a ambas objeciones, se encuentra en el siguiente párrafo de Problems of Empiricsm (1965):

Pero aún hay una experiencia humana como un proceso realmente existente, y todavía obliga al observador a realizar ciertas acciones, por ejemplo, a producir oraciones de cierta clase. No toda interpretación de las oraciones usadas será tal que la teoría que suministra la interpretación la prediga en la forma en que ha surgido de la situación observable. Tal uso combinado de teoría y acción conduce a una selección, incluso en los casos en que no existe un lenguaje de observación común [....]. La teoría -esto es, una teoría aceptable-tiene una maquinaria sintáctica interna que imita (pero no describe) ciertos rasgos de nuestra experiencia. Esta es la única manera en que la experiencia juzga un enfoque cosmológico general. Dicho enfoque no se elimina porque sus enunciados observacionales digan que debe haber ciertas experiencias que luego no se producen [...] Se elimina si produce oraciones de observación cuando los observadores producen la negación de estas oraciones (Feyerabend, 1965a, pp. 214-215). 
En la teoría pragmática de la observación el epistemólogo reconoce explícitamente un sustrato teóricamente neutral en la observación o experimentación. Este sustrato de comparación inter-teórico está constituido por la respuesta verbal del observador ante una situación observable. La observación es el proceso de interacción física entre el observador y el medio. Esta vivencia que es un evento pragmático o psicológico puede determinarse de una manera directa, es decir, es independiente de las interpretaciones teóricas (Feyerabend, 1958/1981, p. 32.). Por tanto puede constituirse como el núcleo común en función del cual las teorías pueden ser comparadas. Dos teorías inconmensurables pueden compararse por el tipo de respuesta que generan en el observador. La materia de la comparación entre teorías inconmensurables son las predicciones semánticamente no-significativas en cuanto que reproducen o no el comportamiento del observador; es decir, independientemente del significado de las predicciones. Esta base permitiría resolver -según Feyerabend- la aparente contradicción señalada por los críticos.

Feyerabend no dispone aún de los elementos especulativos suficientes para desprenderse completamente del esquema del positivismo lógico y en consecuencia argumenta inconsistentemente bajo sus mismos principios. Se aleja del positivismo lógico en cuanto que las sentencias observacionales ya no se caracterizan por su contenido sino por las condiciones de su producción. No obstante, las sentencias observacionales siguen ocupando un papel central en su modelo de contrastación teórica. Crítica el principio de autonomía de los hechos pero finalmente para salvar la tesis popperiana de la falsación y la posibilidad de comparar teorías inconmensurables recurre a un núcleo observacional constituido por la experiencia -que aunque desprovisto de significado, le concede ciertamente una autonomía-. El juicio de Townsend (1970, pp. 206-207) es pertinente a este respecto en cuanto que señala que Feyerabend deja de aplicar su tesis acerca de la estructura teórica de la observación, a la hora de explicar la observación como un proceso de comprobación empírica.

\section{CRITICA A LA TESIS DE LA ESTABILIDAD DEL SIGNIFICADO}

El principio de autonomía de los hechos está en directa relación con el principio de estabilidad del significado, lo cual es entendido por Feyerabend, -junto con el principio de deducibilidad-como otro de los pilares fundamentales sobre los cuales descansa el positivismo lógico ${ }^{11}$, y particularmente, la teoría de la reducción de Nagel y la teoría de la explicación de Hempel y Oppenhein.

Feyerabend (1962/1989, pp. 41-42) define el principio de deducibilidad como aquel que postula que toda nueva teoría no es más que una consecuencia lógica de su predecesora. De aquí la posibilidad y la exigencia de explicar toda teoría mediante la reducción de sus principios a las leyes y principios de las teorías que la anteceden; y que las teorías en un determinado dominio sean consistentes en un sentido lógico estricto.

La tesis de la estabilidad del significado dicta -según Feyerabend (1962/1989, pp. 42-43)- que el significado de los principales términos observacionales permanece intacto e invariable respecto al proceso de reducción o explicación. Los términos claves no cambian de significado al ser abarcados o reducidos a una nueva teoría. Pues, tal como explica Nagel todo término observacional "conserva un significado que puede ser formulado independientemente de [cualquier] teoría [...] Tiene una vida propia, no dependiente de la vigencia de una teoría particular que puede explicar la ley" (Nagel en Feyerabend 1962/1989, p. 49, n. 11). Los términos observacionales de una teoría científica se reducen a una experiencia u observación común la cual garantiza la estabilidad de los significados de los términos observacionales. Luego la interpretación de los términos observacionales no dependería del estatuto del conocimiento.

La primera dificultad que advierte Feyerabend contra la tesis de la estabilidad es la presencia de supuestos ontológicos en el mismo lenguaje observacional. Muestra que no solo los términos teóricos, sino también aquellos que los positivistas reconocen como términos observacionales, al explicar o describir las características observables del mundo, suponen tesis ontológicas que determinan su significado. El lenguaje observacional designa objetos o situaciones a las que se le predican ciertas propiedades y relaciones con otros entes. El significado de este lenguaje observacional depende del universo ontológico en el que se interpreta dicho objeto. Ahora bien, muchos de estos supuestos ontológicos han sido falseados a lo largo del progreso científico y han exigido la adopción de una nueva ontología. Esta nueva ontología supone una nueva heurística del mundo con sus respectivos cambios en la significación del lenguaje. Queda así refutada para el vienés (1958/1981, pp. 20-21 y pp. 29-33; 1960/1981a, pp. 39-43; 1962/1989, p. 125 у pp. 138-139) la tesis de la estabilidad del significado. 
En sus característicos razonamientos por reductio ad absudum, Feyerabend muestra la tensión existente entre la tesis de la estabilidad y la máxima de que toda sentencia debe ser comprobada a través de los enunciados observacionales, los cuales son susceptibles de ser verificados intersubjetivamente. La contradicción interna entre estas dos máximas del positivismo lógico aparece -según Feyerabend (1958/1981) - cuando se descubre que todo "todo lenguaje observacional positivista está basado en una ontología metafísica" (pp. 20-21). Pues si se pretende comprobar que las connotaciones ontológicas de los términos han emergido de una determinada investigación empírica -cumpliéndose así la máxima de comprobación empírica- quedaría invalidado el principio de invariancia del significado, ya que en el mismo momento que los términos hubieran adquirido una significación particular, la tesis de la estabilidad hubiera sido violada. Tampoco es posible comprobar si las consecuencias ontológicas de un lenguaje son incorrectas pues en ese caso también quedaría invalidada la tesis de invariancia del significado.

También dirige una crítica inmanente a Nagel quien sostiene, según el vienés, una teoría contextual del significado y, al mismo tiempo, la tesis de la estabilidad del significado. Los principios de las antiguas teorías -señala Feyerabend- se muestran, usualmente, inconsistentes con los principios de las nuevas teorías corroboradas. Luego es necesario sustituir los viejos principios por los de la nueva teoría, lo cual conduce a la consiguiente eliminación de los antiguos significados y, por tanto, a la violación del principio de invariancia del significado. En orden a ser consecuente con la teoría contextual del significado debe quebrantarse el principio de estabilidad del significado. No se puede ser fiel -asegura el epistemólogo (1962/1989, p. 125)- simultáneamente a ambas tesis.

Feyerabend (1962/1989, pp. 93-94) da pruebas de que el principio de invariancia del significado no solo no puede ser considerado como una prescripción metodológica a seguir por los científicos sino tampoco describe la práctica científica real, es decir, lo que realmente ha sucedido en la los episodios más importantes de la historia de la ciencia. En Explanation, Reductión and Empiricism (1962), presenta numerosos episodios de la historia de la ciencia que dan cuenta de la existencia de nociones inconmensurables en cuanto están informadas por ontologías distintas; mostrando así la inadecuación de la tesis de la invariancia del significado. En la Introducción que escribe para el vol. I y II de los Philosophical Papers (1981) sostiene que su tesis 'tesis I' debe ser entendida no solo como una tesis filosófica sino, y sobre todo, como una síntesis y expresión de un procedimiento científico bastante extendido. Por un lado, puede ser leída como una tesis filosófica en cuanto subraya que las observaciones no tienen una carga teórica sino que son completamente teóricas. Pero, por otro, también puede ser leída como una tesis histórica que revela cómo los científicos hacen uso de teorías para reestructurar tanto los problemas abstractos como los mismos fenómenos. A través del estudio de numerosos pasajes de la historia de la ciencia el autor va elaborando y reforzando la tesis que quiere demostrar.

Feyerabend (1962/1989, pp. 79-94) expone la imposibilidad de definir la noción de ímpetus en los términos descriptivos de la teoría de Newton. Muestra que en las dos teorías resulta cuantitativamente el mismo movimiento pues la magnitud sugerida por el momentum -propuesto como el análogo perfecto de ímpetus- es idéntica a la medida sugerida por el ímpetus. No obstante ambos términos son entre sí estrictamente inconmensurables. Esto se debe, en primer lugar, a que dichas teorías confieren diferentes significados a un mismo y único término como es el de 'fuerza'. Mientras que en la primera se entiende por fuerza el principio inherente que impulsa al cuerpo en movimiento, en la segunda más que la causa es el resultado del movimiento. En segundo lugar, porque la teoría del ímpetus implica leyes que son inconsistentes con la teoría de Newton, por ejemplo, supone que las fuerzas constantes producen velocidades constantes.

También atiende a la inconmensurabilidad existente en la noción de masa $n$ cuanto que pertenece a la física clásica de Newton o a la teoría de la relatividad. La significación propia de la noción de masa en la física clásica lejos de haber sido reducida o incorporada a la teoría de la relatividad ha sido en esta última completamente sustituida o redefinida. En la física pre- relativista la masa es una noción absoluta, una propiedad intrínseca inherente de los objetos físicos. En la teoría de la relatividad, en cambio, es "un concepto relacional cuya especificación queda incompleta sin la indicación del sistema de coordenadas al que se refieren todas las descripciones espaciotemporales" (Feyerabend 1962/1989, pp. 122-123). Estos son algunos de los episodios históricos con los que Feyerabend pretende ilustrar que la sustitución parece ser el proceso que caracteriza la transición de una teoría menos general a otra general, en lugar de la incorporación o de la derivación. 
Pero como dijimos más arriba Feyerabend (1958/1981, p. 20) no se limita a señalar que el principio de invariancia del significado simplemente no describe la práctica científica, sino que demuestra que este tampoco pude ser asumido como un principio normativo o metodológico pues de ser así se seguirían consecuencias problemáticas o negativas para la ciencia, incluso según los criterios valorativos del positivismo lógico.

Primero Feyerabend (1962/1989, pp. 98-102) explica que exigir que el significado de los términos de las teorías futuras sean consistentes con los de las teorías existentes, impide el progreso del conocimiento científico. Pues adoptar esta condición -agrega- conduciría a la eliminación de una teoría, no porque fuera inconsistente con los hechos, sino porque la interpretación de sus términos es inconsistente con los de la teoría imperante. Luego se conservaría una teoría por el solo hecho de ser más antigua, impidiendo la posibilidad de elaborar nuevas teorías y empobreciendo así el contenido empírico de la ciencia, violándose así uno de los principios básicos del empirismo.

Una segunda consecuencia indeseable del principio de estabilidad del significado es el dogmatismo. De la aprobación de solo aquellas teorías que son acordes a una única ontología resulta la consolidación del punto de vista elegido y la consiguiente eliminación de sus contrincantes. El punto de vista elegido se refuerza como una verdad absoluta, se petrifica como "como dogma, siendo completamente protegido de cualquier crítica concebible en nombre de la experiencia" (p. 103).

El epistemólogo vienés objeta también la tesis de un lenguaje uniforme, una versión quizás un poco más modesta que el principio de invariancia del significado, según la cual "se concibe [al lenguaje] en términos tan amplios, tan tolerantes, tan indefinidos y vagos, que sería compatible con cualquier teoría científica" (p. 115). Según esta tesis la interpretación y significado del lenguaje cotidiano permanecería ajeno a los cambios en la superestructura teórica. Luego el lenguaje ordinario con el que se describe el entorno y los resultados finales de los experimentos sería insensible a la transición de teorías científicas.

Con dos razones Feyerabend refuta esta tesis. En primer lugar, señala que todo lenguaje tiene una función comunicativa, la cual no puede ser entendida sin un mensaje. Dicho mensaje recibe su significación o interpretación en el marco de una determinada teoría $y$, a menudo, en el marco de teorías incompatibles y obsoletas. En segundo lugar, advierte que la interpretación de dichos términos cambia a lo largo del tiempo. En el caso de que ciertos términos permanezcan invariables en el lenguaje cotidiano podría deberse al hecho de que la gente no esté interesada en los resultados de la ciencia. Pues al no adoptar las nuevas teorías científicas no pueden modificar los hábitos lingüísticos (1958/1981, pp. 31-32). Feyerabend ilustra esto con dos conceptos cotidianos que cambian de significado al pertenecer a teorías científicas diversas. En el primero muestra cómo la noción de temperatura tal como es interpretada por un hombre lego es inconsistente, o más propiamente, inconmensurable con la interpretación que hace de esta la teoría cinética. Si preguntamos ¿de qué hablamos cuando se dice que la leche tiene una temperatura de diez grados Celsius? El hombre lego simplemente responderá que hablamos de una propiedad térmica de la leche. Dicha respuesta es inconmensurable con la definición que ofrece la teoría cinética según la cual la temperatura es la energía cinética de los constituyentes moleculares del líquido. Se introducen nuevas propiedades o descripciones ontológicas acerca de la temperatura, y con ellas cambia el significado o interpretación del término cotidiano que la designa, de modo análogo a lo que sucede en las teorías científicas (1962/1989, pp. 127-130). El segundo ejemplo versa sobre el par conceptual 'arriba y abajo'. En el tiempo de Tales y Jenófanes estos términos se usaron de un modo absoluto, es decir, sin referencia a ningún centro específico. Este uso contenía implícitamente dos supuestos: primero supone que todo objeto material se encuentra bajo la influencia de una fuerza; segundo que esta fuerza actúa en una dirección privilegiada en el espacio que ha de ser considerada como anisotrópica. Ahora bien, la física Newtoniana remplaza la noción anisotrópica del espacio por una isotrópica, produciendo así una sustitución del significado de la antípoda. El par de conceptos, a partir de ella debe ser interpretado como una relación entre la dirección del movimiento y un centro que ha sido fijado con anterioridad (1960/2005, pp. 305-307; 1962/1989, pp. 130-133).

De este modo, Feyerabend (1962/1989) postula que tanto los lenguajes de los sistemas altamente teóricos como los lenguajes cotidianos contienen principios ontológicos. Ambos "han sido introducidos en orden a dar expresión a alguna teoría o algún punto de vista, y por consiguiente contienen una ontología bien desarrollada y, a veces, muy abstracta" (p. 116). Aun cuando esta no esté explícitamente formulada, está implícitamente patente en el modo en el modo en que se usan los términos. Las diferentes significacio- 
nes, o más propiamente, la inconmensurabilidad que podemos advertir entre los principales términos de una teoría a otra son resultado o consecuencia de una sustitución ontológica. Una nueva teoría supone una nueva ontología la cual "implica cambios de perspectiva tanto respecto a los rasgos observables como a los rasgos no observables del mundo, y cambios correspondientes en el significado de los términos incluso más 'fundamentales' del lenguaje empleado" (p. 39).

El filósofo de las ciencias (1958/1981, p. 21 y 1966a, pp. 416-417) devela los supuestos ontológicos implícitos en el lenguaje cotidiano y en los enunciados observacionales significativos de las teorías científicas, demostrando que ellos no son el resultado de observaciones puras sino que implican supuestos ontológicos acerca del mundo. Y aún más, muestra tácitamente que el mismo criterio empirista de significado como el mismo principio de estabilidad del significado no son más que el intento implícito de defender dogmáticamente una determinada ontología empirista y anti-metafísica.

\section{CONCLUSIÓN}

En su teoría pragmática de la observación Feyerabend da pruebas de cómo el significado de las oraciones observacionales depende de los elementos metafísicos u ontológicos que atraviesan las teorías. Propone un análisis pragmático según el cual se distinguen las propiedades pragmáticas del lenguaje y su interpretación. Con respecto a la interpretación asegura que el sentido de las proposiciones lo confieren los presupuestos desde los cuales se explica la naturaleza de lo que se observa. Ahora, tales presupuestos sobre la naturaleza del mundo no pueden ser comprobados empíricamente y cuanto tales el positivismo lógico los reconoce como metafísicos. Y he aquí la primer paradoja frente a la cual se encuentra un modelo axiomático de ciencia que entiende por metafísica todo aquello que es ajeno al quehacer científico. Pues las sentencias observacionales -señala el vienés- solo pueden ser significativas en la medida que se reconocen los elementos metafísicos como componentes suyos.

Dando un paso más, Feyerabend argumenta que si el significado de las sentencias observaciones depende de los supuestos ontológicos de las teorías debe admitirse que una sustitución de teorías implica una consiguiente modificación del significado de sus términos. Esta tesis, que constituye un antecedente de su doctrina de la inconmensurabilidad, supone una dificultad adicional para los intentos del positivismo ló- gico por definir la ciencia. Pues al negar un significado estable y unívoco en las oraciones observacionales o protocolares Feyerabend destruye el principio de autonomía de los hechos, y con él al modelo de comprobación teórica, $y$, en definitiva, al mismo criterio con el que el positivismo lógico busca garantizar la objetividad científica y dar cuenta del progreso científico.

La crítica que Feyerabend dirige contra el positivismo no se limita a invertir el modelo positivista del significado sino que demuestra cómo la ciencia descansa en definitiva en aquellos elementos que el positivismo reconoce como metafísicos. Mientras el positivismo procura delimitar o demarcar la empresa científica de aquellos elementos, Feyerabend se esfuerza por dar cuenta cómo el sentido de las proposiciones observacionales depende de los elementos metafísicos que atraviesan la teoría. Ahora bien, al negar a las sentencias observacionales como los núcleos estables, neutrales y objetivos de las teorías científicas, Feyerabend no solo está atacando los criterios positivistas del significado, o al modelo positivista de comprobación teórica, sino que en definitiva su crítica alcanza los distintos intentos del positivismo lógico por definir la ciencia en una oposición dialéctica con la metafísica.

En un sentido negativo su teoría pragmática de la observación puede ser interpretada como una denuncia de las falsas dialécticas instituidas por el positivismo lógico entre sentencias observacionales y teóricas, entre ciencia y metafísica. Pero también puede ser leída en un sentido positivo, es decir, como el reclamo de una explicación más justa de la ciencia y de un nuevo modo de entender la relación cienciametafísica. En continuidad con su posterior doctrina de la inconmensurabilidad, junto con su respectiva propuesta de un pluralismo teórico y su anarquismo epistemológico, su teoría del significado puede ser vista como el primer foco de discusión a través del cual Feyerabend busca despertar un debate en torno al cual pueda generarse una filosofía de la ciencia más atenta a las complejidades y contingencias históricas de la práctica científica.

Ahora bien esta hermenéutica de su teoría pragmática de la observación permite explicar el posterior abandono de Feyerabend de las cuestiones del lenguaje. La razón de su abandono de los análisis lingüísticos que lo ocuparon durante gran parte de sus publicaciones de los años 60 y principios de los 70 estriba en que a Feyerabend no le interesa, ni siquiera en tales artículos tempranos, terciar o participar en el proyecto de erigir una teoría positivista del lenguaje, ni en oponer a ella una nueva teoría del lenguaje. 
Su intención en estos años se concentra en denunciar el falso fundamento sobre el cual se erige un modelo axiomático de ciencia y para demostrarlo, a modo de una consecuencia accidental, formula una teoría pragmática del significado.

Entre los escritos tempranos y la obra posterior del vienés no hay un salto abrupto e inconsistente, como señala Preston (1999, p. 235). Hay, por el contrario, entre ellos una perfecta unidad lógica. Feyerabend expresa su crítica en los mismos términos con los que se plantea y desarrolla este modelo formal de cien- cia, es decir, desde los enfoques lógicos y lingüísticos que predominaban en el positivismo lógico. Pero una vez que con su teoría pragmática de la observación y su doctrina de la inconmensurabilidad demuestra la imposibilidad de reducir lógicamente los términos de una teoría a la otra, y el contrasentido del principio de autonomía de los hechos la utilización de tales recursos carece de sentido, De aquí que a su preocupación inicial por los asuntos del significado la califique posteriormente como inútil para una teoría del conocimiento y de la ciencia.

\section{NOTAS}

1 Para facilitar la lectura, las citas de las obras de Paul Feyerabend tendrán doble fecha. La primera se refiere al año de la primera edición y la segunda a la publicación consultada. El objetivo de la doble fecha es dar cuenta de un orden cronológico de las publicaciones y, al mismo tiempo, remitir al lector a los lugares precisos donde pueda cotejar las citas textuales, las paráfrasis y las referencias generales.

2 En 1951, en la disertación de su tesis doctoral, emplea la noción de inconmensurabilidad -aunque no el término mismo- para rechazar el rol que el empirismo lógico concede a las oraciones observacionales en la comprobación de teorías. Cf. Feyerabend (1951). Se puede encontrar una versión más abreviada en Feyerabend (1958/1981).

3 Por otro lado, entre los especialistas en Feyerabend existen otras lecturas como las de Richard Rorty (1980) y lan Hacking (1975), quienes aseguran que el vienés no solo no formuló ninguna teoría del significado sino que desprecia tales cuestiones. Tal hipótesis pretende tener su fundamento en los numerosos pasajes donde Feyerabend rechaza toda consideración del quehacer científico desde un enfoque lógico-lingüístico (cf. Feyerabend (1954/1955, pp. 480-483; 1956, p. 96 n. 4; 1960, p. 247; 1960/1981b, pp. 219-220; 1961/1999, p. 75; 1963, p. 320 $1964 a$, pp. 250 y ss; $1965 a$, p. 226 n. 10 , p. 246 n. 114 , p. 247 n. 116 , p. 249 n. 118 , p. 151 n. 132 , p. 252 n. 137 y pp. $256-257$ n. $151 ; 1966$ b, p. 9; 1975/1999, pp. 197 198) y Hoyningen-Huene (1995), p. 385.

4 A modo de respuestas o soluciones a tal interrogante -las cuales son ciertamente irreductibles con las que se exponen en el presente trabajo- se pueden ver los estudios de Downes, 2002, 160; 1998, 97-98; Farrell 2003, 106-107; Gentile 2007, 126; Preston, 1998, 82
Preston, Lamb, 2000, xvi; Van Fraassen 2000, 33 y ss.

5 Feyerabend asume la concepción de Popper respecto al contenido empírico. Popper distingue entre el contenido lógico de una teoría y el contenido empírico. Entiende por contenido empírico el conjunto de sentencias básicas que constituyen falseadores potenciales de una teoría (Cf. Popper 1972, 385).

6 Feyerabend sostiene que en 1930 Popper, Carnap y Neurath defendieron con excelentes argumentos la teoría pragmática de la observación. Pero agrega que más tarde la abandonaron (cf. Feyerabend 1962/1981b, pp. 49 y ss.; 1965a, p. 152 y 1965/1981, p. 125). Para una discusión crítica de esta tesis se puede ver Preston (1997, pp. 45 y ss.).

7 Por primer positivismo Feyerabend (1958/1981, p. 30, n. 20) entiende tanto el instrumentalismo como el reduccionismo semántico de Carnap.

8 Feyerabend asume una perspectiva kantiana por la cual adopta una distinción entre el mundo que experimentamos, la concepción teórica del mundo y el mundo mismo. No obstante asegura que el mundo que experimentamos como real depende de las teorías desde las cuales lo interpretamos, y que estas experiencias cambian tan pronto como son sustituidas las teorías que contribuyen a la constitución de estas experiencias (Cf. Feyerabend 1960/2005, pp. 299-300 y 1958/1981, p. 31).

9 Preston (1997, pp. 40-41) afirma que después de 1965 Feyerabend abandona su tesis acerca de la naturaleza teórica de la observación en cuanto que considera que esta fue empíricamente refutada. Efectivamente en Reply to Criticism. Comments on Smart, Sellars and Putnam (1965/1981, p. 128), Feye- rabend explica que ciertos experimentos han demostrado que un cambio de creencias o ideas afecta necesariamente el modo de percibir visualmente el mundo. En una nota al pie Feyerabend cita los descubrimientos de Michotte concretamente su obra The Perception of Causality (1965/1981, p. 128, n. 9.) donde prueba que en ciertas situaciones percibimos visualmente relaciones causales que están en contradicción con nuestro sentido común; mientras que en otras circunstancias las relaciones causales reales aparecen como imposibles de percibir visualmente. No obstante, el reconocimiento de Feyerabend a estos estudios no supone -tal como señala Preston- un abandono de su tesis acerca del carácter teórico de la observación. Más bien implica una moderación o profundización de dicha tesis. Feyerabend no cambia de parecer respecto a si nuestras creencias dan forma o no a nuestra percepción; sino que precisa que no todo cambio de creencias tiene como resultado un cambio perceptual. $\mathrm{O}$, dicho de otro modo, no toda percepción está abierta a una revisión a la luz de un cambio de creencias.

10 Feyerabend no solo ataca al principio de autonomía de los hechos sino también a todas aquellas tesis que se siguen o fundan en este (Cf. Feyerabend, 1958; 1958/1981, pp. 32-33; 1959a, p. 82; 1960/1981a, pp. 37-43; 1960/1999, pp. 16-49; 1960/2005, pp. $277-312$; $1962 / 1981 b$, pp. $45-$ 46; 1965 a, p. 198 y pp. $219-224$, n. 8; 1969/1981, pp. 132-135).

11 Tanto Eric Oberheim (2006, p. 52) como John Preston (1997, p. 33) y Nélida Gentile (2007, p. 125) señalan que Feyerabend adjudica erróneamente una versión fuerte del principio de estabilidad del significado a Carnap o a los positivistas lógicos en general. 
Achinstein, P. (1964). On the Meaning of Scientific Terms. Journal of Philosophy, 61, pp. 497-509. http://dx.doi. org/10.2307/2022847

Achinstein, P. (1968). Concepts of Science. Baltimore: Johns Hopkins University Press.

Bogen, J. y Woodward J. (1992). Observations, Theories and the Evolution of the Human Spirit. Philosophy of Science, 59, pp. 590611. http://dx.doi.org/10.1086/289697

Boyd, R. (1992). Constructivism, Realism and Philosophical Method, Inference Explanation, and other Frustrations. En Earman, J. (ed.). Essays in the Philosophy of Science. Berkeley: University of California Press, pp. 131- 198.

Bronncano, F. (1999). Introducción. Uno de los nuestros. Ambigüedad y Armonía. Barcelona: Paidós, pp. 7-32.

Butts, R. (1966). Feyerabend and the Pragmatic Theory of Observation. Philosophy of Science, 33, pp. 383-394. http://dx.doi. org/10.1086/288110

Chalmers, A. (1985). Galileo's Telescopic Observations of Venus and Mars. Bristish Journal for the Philosophy of Science, 36, pp. 175-184. http://dx.doi.org/10.1093/ bjps/36.2.175

Churchland, P. (2000). To transform the Phenomena. En Preston, J., Munévar, G. y Lamd, D. (eds.). The Worst Enemy of Science? Essays in memory of Paul Feyerabend. New York: Oxford University Press, pp. 148-158.

Farrell, R. (2000). Will the Popperian Feyerabend Please Step Forward: Pluralistic, Popperian Themes in the Philosophy of Paul Feyerabend. International Studies in the Philosophy of Science, 14, pp. 257-266. http:// dx.doi.org/10.1080/026985900437764

Farrell, R. (2003). Feyerabend and Scientific Values. Tightrope-Walking Rationality. Netherlands: Kluwer Academic Publishers. http://dx.doi.org/10.1007/97894-017-1542-3

Feyerabend, P. (1951). Zur Theorie der Basissätze (Dis), Universität Wien.

Feyerabend, P. (1954/1955). Review of Wittgenstein's Philosophical Investigations. The Philosophical Review, 64, pp. 449-483. http://dx.doi. org/10.2307/2182211

Feyerabend, P. (1956). A Note on the Paradox of Analysis. Philosophical Studies, 7, pp. 92-96. http://dx.doi.org/10.1007/ BF02221761
Feyerabend, P. (1958). Complementarity. Proceedings of Aristotelian Society, Suppl. vol. 32, pp. 75-104.

Feyerabend, P. (1958/1981). An attempt at a realistic interpretation of experience. Realism, rationalism and scientific method (volume 1: Philosophical Papers). Cambridge: Cambridge University Press, pp. 17-36.

Feyerabend, P. (1959a). Comments on Sellars. The Language of Theories. En Feigl, H. y Maxwell, G. (eds.). Current Issues in the Philosophy of Science. Symposia of Scientists and Philosophers. Proceedings of Section L of the American Association for the Advancement of Science. New York: Holt, Rinehart-Winston.

Feyerabend, P. (1959b). Comments on Hill's "Quantum Physics and Relativity Theory". En Feigl, H. y Maxwell, G. (eds.). Current Issues in the Philosophy of Science. Symposia of Scientists and Philosophers. Proceedings of Section $L$ of the American Association for the Advancement of Science. New York: Holt, Rinehart-Winston.

Feyerabend, P. (1960). Review of Patterns of Discovery. An Inquiry into the Conceptual Foundations of Science by N. R. Hanson. The Philosophical Review, 69, pp. 247-252. http://dx.doi. org/10.2307/2183509

Feyerabend, P. (1960/1981a). On the Interpretation of scientific theories. Realism, rationalism and scientific method (volume 1: Philosophical Papers). Cambridge: Cambridge University Press, pp. 37-43.

Feyerabend, P. (1960/1981b). Professor Bhom's Philosophy of Nature. Realism, rationalism and scientific method. Philosophical Papers (volume 1). Cambridge: Cambridge University Press, pp. 219-235.

Feyerabend, P. (1960/1999). The Problem of the Existence of Theoretical Entities. En Preston, J. (ed.). Paul K. Feyerabend: Knowledge, Science and Relativism (volume 3: Philosophical Papers). Cambridge: Cambridge University Press, pp. 16-49.

Feyerabend, P. (1960/2005). El problema de la existencia de las entidades teóricas. Scientiae Studia, 3, pp. 277-312. http://dx.doi.org/10.1590/S167831662005000200008

Feyerabend, P. (1961). Review of An Introduction to the Logic of the Sciences by Rom Harré. British Journal for the
Philosophy of Science, 12, pp. 245250. http://dx.doi.org/10.1093/bjps/ XII.47.245

Feyerabend, P. (1961/1999). Knowledge without foundation. En Preston, J. (ed.). Paul K. Feyerabend: Knowledge, Science and Relativism (volume 3: Philosophical Papers). Cambridge: Cambridge University Press, pp. 50-77.

Feyerabend, P. (1962/1981a). Hidden variables and the argument of Einstein, Podolsky and Rosen. Realism, rationalism and scientific method (volume 1: Philosophical Papers). Cambridge: Cambridge University Press, pp. 298-342.

Feyerabend, P. (1962/1981b). Explanation, Reduction and Empiricism. Realism, rationalism and scientific method (volume 1: Philosophical Papers). Cambridge: Cambridge University Press, pp. 44-96.

Feyerabend, P. (1962/1989). Límites de la ciencia. Explicación, reducción y empirismo. Barcelona: Paidós.

Feyerabend, P. (1963). Review of Erkenntnislehre by Victor Kraft. British Journal for the Philosophy of Science, 13, pp. 319-323. http://dx.doi.org/10.1093/ bjps/XIII.52.319

Feyerabend, P. (1963/1999). How to be a good empiricist: a plea for tolerance in matters epistemological. En Preston, J. (ed.). Paul K. Feyerabend: Knowledge, Science and Relativism (volume 3: Philosophical Papers). Cambridge: Cambridge University Press, pp. 78-103.

Feyerabend, P. (1964a). Review of Scientific Change by A. Crombie. The British Journal for the Philosophy of Science, 15, pp. 244-254. http://dx.doi.org/10.1093/ bjps/XV.59.244

Feyerabend, P. (1964b). Review of The Concept of the Positron. A Philosophical Analysis by N. R. Hanson. The Philosophical Review, 73, pp. 264-266. http:// dx.doi.org/10.2307/2183342

Feyerabend, P. (1964c). A Note on the Problem of Induction. Journal of Philosophy, 61, pp. 349-353. http://dx.doi. org/10.2307/2023161

Feyerabend, P. (1964/1981). A Note on the Problem of Induction. Realism, rationalism and scientific method (volume 1: Philosophical Papers). Cambridge: Cambridge University Press, pp. 203-206.

Feyerabend, P. (1965a). Problems of Empiricism. En Colodny, R. (ed.). Beyond the 
Edge of Certainty. Essays in Contemporary Science and Philosophy. Pittsburg. CPS Publications in the Philosophy of Science, pp. 145-260.

Feyerabend, P. (1965b). Review of Conjectures and Refutations. The Growth of Scientific Knowledge by K. R. Popper. Isis, 56, p. 88. http://dx.doi. org/10.1086/349934

Feyerabend, P. (1965/1981). Reply to Criticism. Comments on Smart, Sellars and Putnam. En Realism, rationalism and scientific method (volume 1: Philosophical Papers). Cambridge: Cambridge University Press, pp. 104-131.

Feyerabend, P. (1966a). Dialectical Materialism and the Quantum Theory. Slavic Review, 25, pp. 414-417. http://dx.doi. org/10.2307/2492853

Feyerabend, P. (1966b). Herbert Feigl: A biographical Sketch. En Feyerabend P. y Maxwell, G. (eds.). Mind, Matter and Method: Essays in Philosophy and Science in Honor of Herbert Feigl. Minneapolis: University of Minnesota Press, pp. 3-13.

Feyerabend, P. (1967). The Mind-Body Problem. Continuum, 5, pp. 35-49.

Feyerabend, P. (1969/1981). Science without Experience. Realism, rationalism and scientific method (volume 1: Philosophical Papers). Cambridge: Cambridge University Press, pp. 132-135.

Feyerabend, P. (1970/1989). Contra el método. Esquema de una teoría anarquista del conocimiento. Barcelona: Ariel.

Feyerabend, P. (1975). Imre Lakatos. British Journal for the Philosophy of Science, 26, pp. 1-18. http://dx.doi.org/10.1093/ bjps/26.1.1

Feyerabend, P. (1975/1992). Contra el método. Esquema de una teoría anarquista del conocimiento. Madrid: Tecnos.

Feyerabend, P. (1975/1999). Let's Make More Movies. En Preston, J. (ed.). Paul K. Feyerabend: Knowledge, Science and Relativism (volume 3: Philosophical Papers). Cambridge: Cambridge University Press, pp. 192-199.

Feyerabend, P. (1977). Review of Changing Patterns of Reconstruction. British Journal for the Philosophy of Science, 28, pp. 351-382. http://dx.doi.org/10.1093/ bjps/28.4.351

Feyerabend, P. (1978/1982). La ciencia en una sociedad libre. Madrid: Veintiuno Editores.

Feyerabend, P. (1981). Introduction: Scientific Realism and Philosophical Realism. Realism, rationalism and scientific method (volume 1: Philosophical Papers). Cambridge: Cambridge University Press, pp. 3-16

Feyerabend, P. (1987/1995). Sobre Prigogine. Entrevista realizada por Christian Delacampagne. Zona Erógena, 23, pp. 1-15.

Feyerabend, P. (1991). Three Dialogues on Knowledge. Cambridge: Basil Blackwell.

Feyerabend, P. (1993/2008). Against Method ( $3^{\text {th }}$ ed.). London: Verso.

Feyerabend, P. (1994/1995). Matando el tiempo. Autobiografía. Madrid: Debate.

Feyerabend, P. (1994/1999). La conquista de la abundancia. La abstracción frente a la riqueza del ser. Barcelona: Paidós.

Feyerabend, P. (1996/1999). Ambigüedad y armonía. Barcelona: Paidós.

Gentile, N. (2007). El camino de Feyerabend: crítica, proliferación y realismo. Filosofía Unisinos, 8, pp. 109-127.

Hacking, I. (1975). Why Does Language Matter to Philosophy? Cambridge: Cambridge University Press. http://dx.doi. org/10.1017/CBO9780511627873

Hardcastle, V. (1994). The Image of Observables. British Journal for the Philosophy of Science, 45, pp. 585-597. http:// dx.doi.org/10.1093/bjps/45.2.585

Hentschel, K. (1985). On Feyerabend's Version of Mach's Theory of Research and its Relations to Einstein. Studies in History and Philosophy of Science, 16, pp. 387-394. http://dx.doi. org/10.1016/0039-3681(85)90019-6

Hoyningen-Huene, P. (ed.). (1995). Two Letters of Paul Feyerabend to Thomas S. Kuhn on a Draft of The Stucture of Scientific Revolutions. Studies in History and Philosophy of Science, 26, pp. 353387. http://dx.doi.org/10.1016/00393681(95)00005-8

Hooker, C. (1973). Empiricism, Perception and Conceptual Change. Canadian Journal of Philosophy, 3, pp. 59-75.

Hull, R. (1972). Feyerabend's Attach on Observation Sentences. Synthese, 23, pp. 374-399. http://dx.doi.org/10.1007/ BF00636292

Klimovsky, G. (2001). Las desventuras del conocimiento científico. Una introducción a la epistemología (5a ed.). Buenos Aires: A-Z Editora.

Kordig, C. (1971). The theorie ladness of obervation. Review of Metaphysics, 24 pp. 448-484.

Oberheim E., Hoyninguen-Huene P. (1997). Incommensurability, Realism and Me- taincommensurability. Theoria, 12, pp. 447-465.

Oberheim E., (2006). Feyerabend's Philosophy. Berlín: Walter de Gruyter. http:// dx.doi.org/10.1515/9783110891768

Popper, K. (1972). Conjectures and Refutations: The Growth of Scientific Knowledge $\left(4^{\text {th }} \mathrm{ed}\right)$. London: Routledge.

Preston, J. (1997). Feyerabend. Philosophy, Science and Society. Oxford: Blackwell.

Preston, J. (1999). Reviews Symposia: Radical Fallibilism vs. Conceptual Analysis: The Significance of Feyerabend's Philosophy of Science. Metascience, 8, pp. 233-243. http://dx.doi.org/10.1007/BF02913265

Putnam, H. (1965). How Not to Talk About Meaning. En Cohen R., y Wartofsky, W. (eds.) Boston Studies in Philosophy of Science (volume 2: In Honor of Philipp Frank). New York: Humanities Press.

Quine, W. (1986). La relatividad ontológica y otros ensayos. Madrid: Tecnos.

Quine W. (1992). La búsqueda de la verdad. Barcelona: Crítica.

Quine W. (1993). In Praise of Observation Sentences. The Journal of Philosophy, 40, pp. 107-116. http://dx.doi. org/10.2307/2940954

Rorty, R. (1980). Philosophy and the Mirror of Nature. Oxford: Basil Blackwell.

Shapere, D. (1966), Meaning and the Scientific Change. En Colodny, R. (ed.). Mind and Cosmos. Pittsburgh: Pittsurgh University Press, pp. 41-85.

Shapere, D. (1981). Meaning and Scientific Change. En Hacking, I. (ed.). Scientific Revolutions. Oxford: Oxford University Press.

Shea, W. (1971). Beyond Logical Empiricism. Dialogue, 10, pp. 223-242. http://dx.doi. org/10.1017/S0012217300050022

Townsend, B. (1970). Feyerabend's Pragmatic Theory of Observation and the Comparability of Alternative theories. Proceedings of the Biennial Meeting of the Philosophy of Science Association, pp. 202-211.

Watkins, J. (2000). Feyerabend among Popperians 1948-1978. The Worst Enemy of Science? En J. Preston, J., Munévar, G. y Lamb, D. (eds.). Essays in memory of Paul Feyerabend. New York: Oxford University Press, pp. 47- 57.

Zahar, E. (1981). Second Thoughts about Machian Positivism: A Replay to Feyerabend. British Journal for the Philosophy of Science, 32, pp. 267-276. http:// dx.doi.org/10.1093/bjps/32.3.267 